\title{
Cytogenetic studies on marine ostracods: the karyotype of Gigantocypris muelleri Skogsberg, 1920 (Ostracoda, Myodocopida)
}

\author{
ALICIA MOGUILEVSKY \\ Department of Geology, University College of Wales, Aberystwyth, Dyfed SY23 3DB, U.K.
}

\begin{abstract}
The chromosome complement of a bathypelagic myodocopid ostracod, Gigantocypris muelleri Skogsberg, 1920, is described. The karyotype of this bisexual species consists of $2 n=18(16 \mathrm{~A}+\mathrm{XX})$ for the female and $2 \mathrm{n}=17(16 \mathrm{~A}+\mathrm{XO})$ for the male. These chromosomes are all metacentric and of very similar size, ranging from $19 \mu \mathrm{m}$ to $24 \mu \mathrm{m}$. This is the first description of the karyotype of a marine ostracod.
\end{abstract}

\section{INTRODUCTION}

Most taxonomic studies of Recent species have been concerned solely with carapace and appendage morphology. Although cytogenetic studies on ostracods were made as early as 1898 (Woltereck), the knowledge of their karyotypes remains rudimentary. Woltereck (op. cit.) and other early papers (Schleip, 1909; Schmalz, 1912; Muller-Cale, 1913; Bauer, 1934, 1940) were mainly concerned with the study of gametogenesis and spermatogenesis of freshwater cyprids (Podocopida). Although the chromosome complement of some of those species were also described, it was Dietz (1954, $1955,1958)$ and later Tetart $(1967,1969,1975,1978)$ and Bianchi Bullini \& Bullini (1972) who principally contributed to the knowledge of podocopid ostracod karyotypes.

A good review of previous papers can be found in Tetart $(1975,1978)$ who has published by far the most extensive and thorough cytogenetic work on freshwater ostracods. Over 50 karyotypes of ostracods are known to date, all from freshwater species of the order Podocopida.

The author is not aware of any other cytogenetic study on either myodocopid or marine podocopid ostracods.

\section{MATERIAL AND METHODS}

Gigantocypris muelleri is a bisexual, bathypelagic species belonging to the Cypridinacea within the Myodocopida. It has been widely reported from the Indian, Antarctic and Atlantic Oceans. The upper and lower depth limits of this species in the N.E. Atlantic are $700 \mathrm{~m}$ and $1500 \mathrm{~m}$ respectively (Moguilevsky \& Gooday, 1977).

G. muelleri is one of the largest ostracod species. Females are larger than males. Their size ranges between $1.29 \mathrm{~cm}-1.51 \mathrm{~cm}$ for the female, and $1.18 \mathrm{~cm}-1.32 \mathrm{~cm}$ for the male (Moguilevsky \& Gooday, op. cit.).
Whereas the majority of oceanic planktonic species release their eggs into the surrounding water, the females of $G$. muelleri retain them in a brood chamber where they develop before being released as free swimming juveniles. Specimens of Gigantocypris muelleri were collected during cruises of RRS 'Discovery' in the N.E. Atlantic, in June 1981 (Cruise 121, S.W. of Azores) by the author, and in August/September 1983 by Dr. C. Ellis (Cruise 140, N.E. and S.E. of Azores). Full station data can be obtained from the Cruise Reports (Angel $e t$ al., 1981; Herring et al., 1983).

Specimens were recovered with an RMT $1+8$ combination net (Baker et al., 1973). This net has an acoustically controlled opening and closing mechanism which allows the depth of fishing to be continuously monitored while the net is operating. Water temperature and net speed as well as precise depth values are thus obtained.

Those specimens that appeared most active on arrival on board were placed in beakers containing a solution of $0.1 \%$ Colchicine in sea water and kept in a cool room at $5^{\circ} \mathrm{C}-10^{\circ} \mathrm{C}$ for about 24 hours. This temperature is similar to the in situ water temperature at which the animal normally lives. The material was then fixed and preserved in acetic alcohol (3:1, absolute alcohol and acetic acid).

Tetart $(1975,1978)$, in his study of the chromosomes of freshwater ostracods, used material from the gonads and cells from the digestive tube. In Gigantocypris muelleri it was found that, from a range of different tissues tested, the best results were obtained from preparations of young embryos and testes. Young embryos provided the material for the study of mitotic chromosomes (Figs. 1, 2, 3). Testes were used to study the sex chromosome system (Fig. 4).

A gravid female was placed in a petri dish containing acetic alcohol, and the embryos removed from the brood chamber, measured and the stage of development 


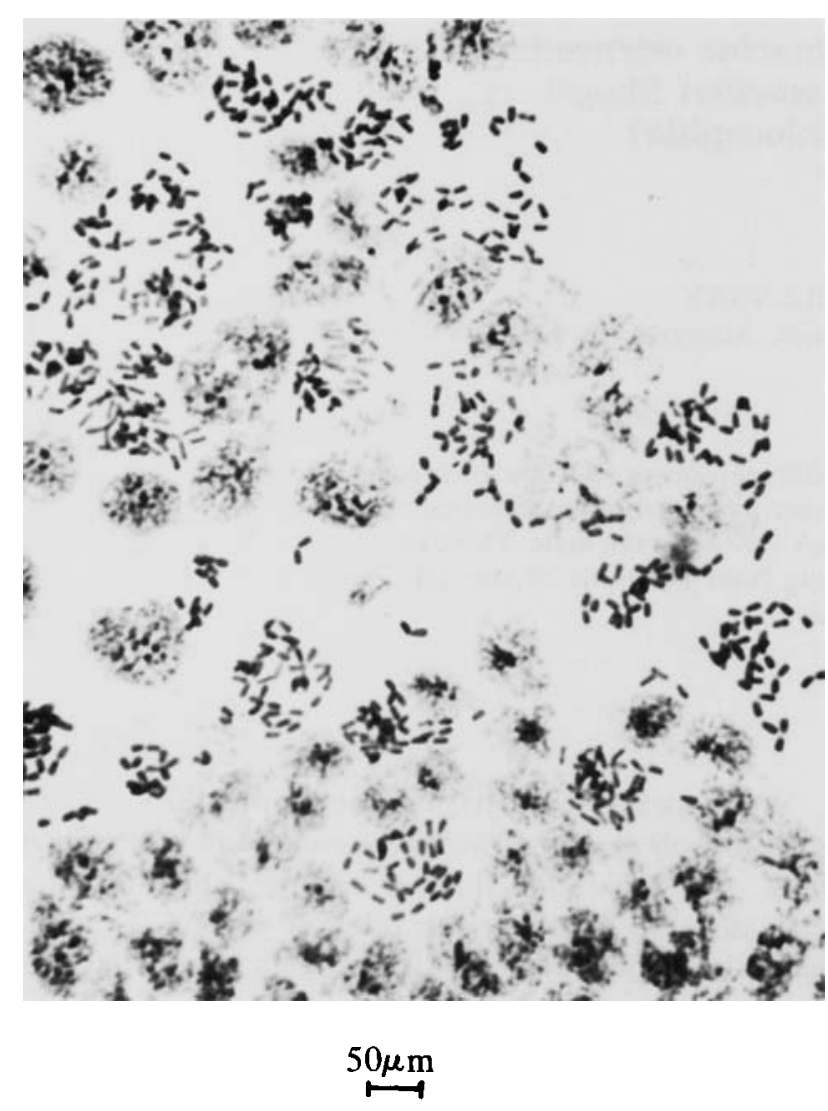

Fig. 1. Gigantocypris muelleri. Low power field of view showing numerous c-mitosis in an embryo squash.

ascertained. Each embryo was then placed on a glass slide with adrop of acetic orcein, gently teased out and spread as very small pieces over the slide. It was then lightly squashed with a cover slip, adding more stain if necessary. The slide was sealed with liquid rubber. After 24 hours (but not more than 48 hours) the rubber seal was peeled away, the cover slip floated off in $45 \%$ acetic acid and the tissue dehydrated in absolute alcohol. These preparations were made permanent with Sandeural. All photographs and measurements were carried out on a Carl Zeiss compound microscope, before the slide was made permanent.

The relative lengths and centromeric indices of the mitotic chromosomes were calculated by the method of Macgregor \& Varley (1983).

\section{RESULTS}

The study of cells from testes and young embryos of G. muelleri shows a karyotype composed of a diploid number of 18 for the female and 17 for the male.

The complement is made up of 16 autosomes and $2 \mathrm{X}$ chromosomes in the female and 16 autosomes and one unpaired $\mathrm{X}$ chromosome in the male (XO).

G. muelleri presents a highly symmetrical karyotype. All chromosomes are very similar in form and size. They are also all metacentric or very slightly submetacentric, according to the classification of Macgregor \& Varley (1983). Their centromeric index (c.i. = length of short arm $\times 100 /$ length of whole chromosome) varies from $43.18-50$. They range in size between $19 \mu \mathrm{m}-24 \mu \mathrm{m}$ which is between $4-40$ the size of most chromosomes of freshwater ostracod species (Tetart, 1975, 1978). As Fig. 5 illustrates, the length of the individual chromosomes varies very gradually; this, added to their overall similarity, renders them impossible to identify individually without recourse to further banding techniques.

The idiogram (Fig. 5) is reconstructed from 10 mitotic metaphasic plates of young embryos.

Due to the characteristics of these chromosomes, discussed above, their relative length (r.l.= length of chromosome $\times 100 /$ total length of haploid genome) was calculated taking into account the total length of the diploid genome.
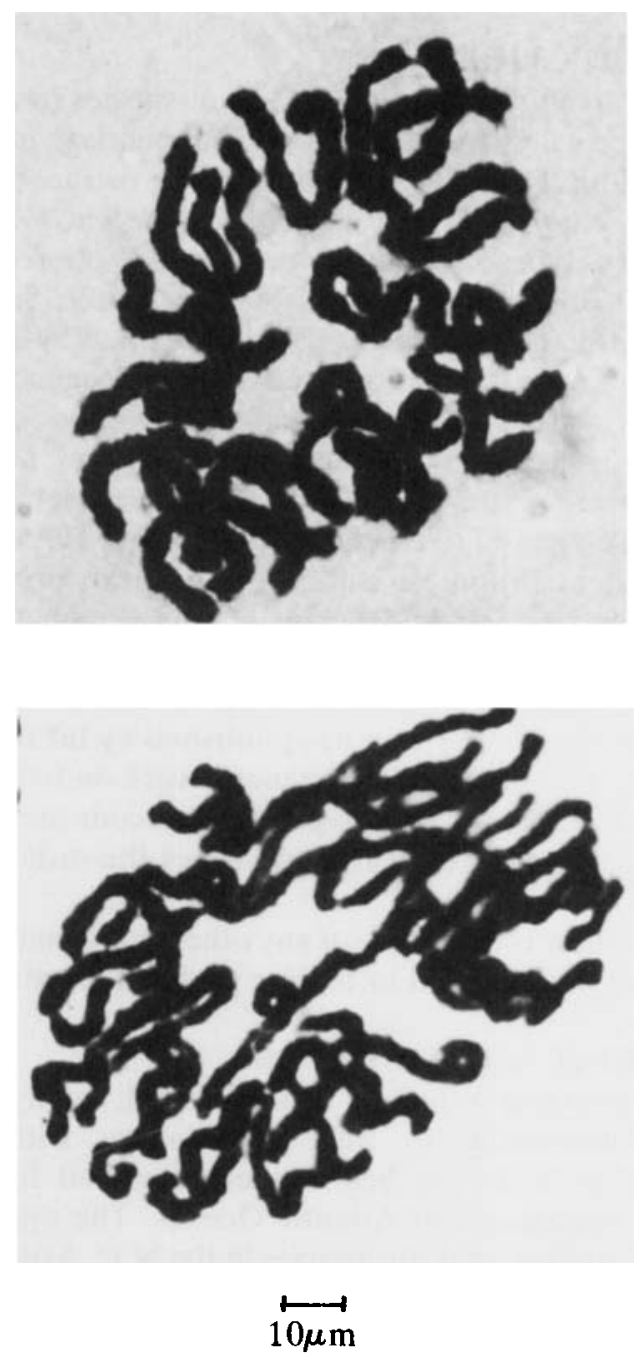

Fig. 2. Gigantocypris muelleri. Early (above) and late (below) mitotic prophase stages in young embryos. 

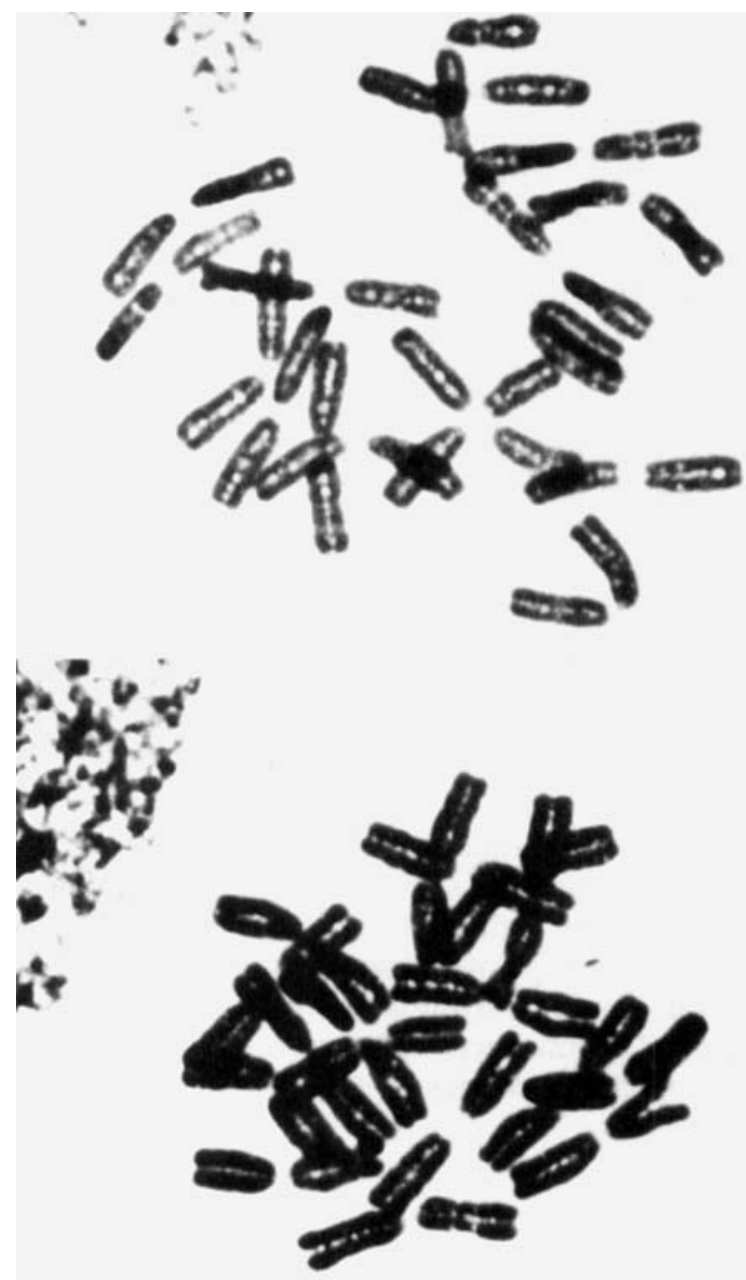

$10 \mu \mathrm{m}$

Fig. 3. Gigantocypris muelleri. C-mitosis in young embryo tissue showing some variation in contraction of the chromosomes.

\section{DISCUSSION}

Tetart (1978) described 42 karyotypes of 24 species of freshwater podocopid ostracods. Of these 24 species, 22 belong to the Cypridacea, one to the Cytheracea and one ot the Darwinulacea. His study shows a diversity of cytogenetic characteristics present in this group. The main differences are in number, size and structure of the chromosomes. Despite these differences, Tetart (op. cit.) divided these karyotypes into two distinctive groups. The first, which he calls "symmetrical" is characterised solely by "acrocentric" chromosomes [chromosomes with the centromere in a distal position are referred to by Tetart $(1975,1978)$ as acrocentric rather than telocentric]. The second or "asymmetrical" group, includes both "acrocentric" chromosomes (the majority), and
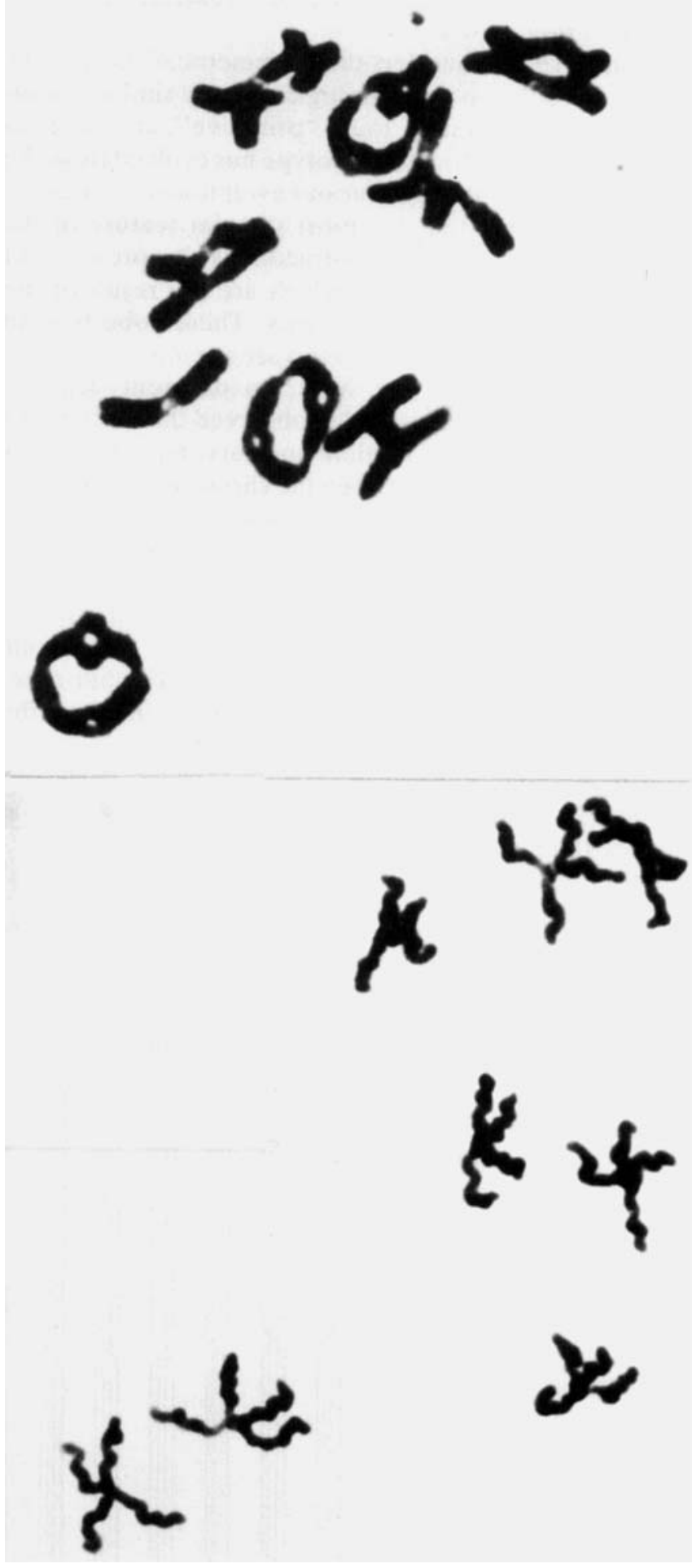

$\stackrel{10 \mu \mathrm{m}}{\longmapsto}$

Fig. 4. Cromosomes of Gigantocypris muelleri at meiosis in the male.

(a) Diakinesis of prophase I showing 8 bivalents and a single unpaired $X$ (arrowed).

(b) Second prophase. 
others which are metacentric or submetacentric and always larger in size.

Tetart (1978) considers the "symmetrical" karyotype, composed solely of morphologically very similar "acrocentric" chromosomes, to be "primitive", and suggests that the "asymmetrical" karyotype has evolved from the "primitive" type through various evolutionary processes. He also remarks that the most singular feature of the karyotypes of freshwater ostracods is the presence of metacentric chromosomes, which are the result of the fusion of "acrocentric" elements. These robertsonian fusions and the loss of autosomes are the most important evolutive processes that have, to different degrees, modified their karyotypes. He observed that for species for which he found more than one karyotype, there was always a relationship between the chromosome number, the number of metacentric chromosomes and the fundamental number. He then suggested that the numerical and morphological differences among the karyotypes of freshwater ostracods show the existence of distinct cytogenetical groups which express the taxonomic divisions within these three superfamilies. Furthermore, within the Cypridacea these differences indicate the presence of distinct taxonomic groupings.

The haploid number of the freshwater ostracods studied by Tetart (op. cit.) is generally low and thus he makes them comparable to numbers found by other authors in copepods.
The karyotype of Darwinula stevensoni, a species of a geologically old, conservative and usually parthenogenetic genus, and the only living member of the superfamily Darwinulacea, shows a great morphological uniformity. It is composed of 11 pairs of 'acrocentric' chromosomes, very similar in size (approximately $1.5 \mu \mathrm{m})$. The haploid number is comparable with the majority of the cyprids but this karyotype differs from all the others in the great uniformity of its components.

Limnocythere inopinata, a bisexual species, is the only cytherid analysed by Tetart. The karyotype of this species is composed of only 14 chromosomes: one pair metacentric and six pairs "acrocentric". The size of the largest metacentric is only about $3 \mu \mathrm{m}$. The very low number of chromosomes of this cytherid species sets it apart from the other freshwater species.

The Cypridacea studied by Tetart (op. cit.) include a number of parthenogenetic species. The diploid numbers of the species studied vary from $20-33$ and the size of the chromosomes from approximately $0.5 \mu \mathrm{m}-6.0 \mu \mathrm{m}$. The diploid numbers of the bisexual cyprid species range from 16-20 (lower than that of parthenogenetic ones). Chromosomes range in size from $0.5 \mu \mathrm{m}-3.0 \mu \mathrm{m}$.

In contrast with Tetart's results on freshwater Podocopina, the karyotype of Gigantocypris muelleri, a highly specialised marine myodocopid ostracod, shows a remarkable "symmetrical" karyotype composed only of metacentric chromosomes of similar relative size. The

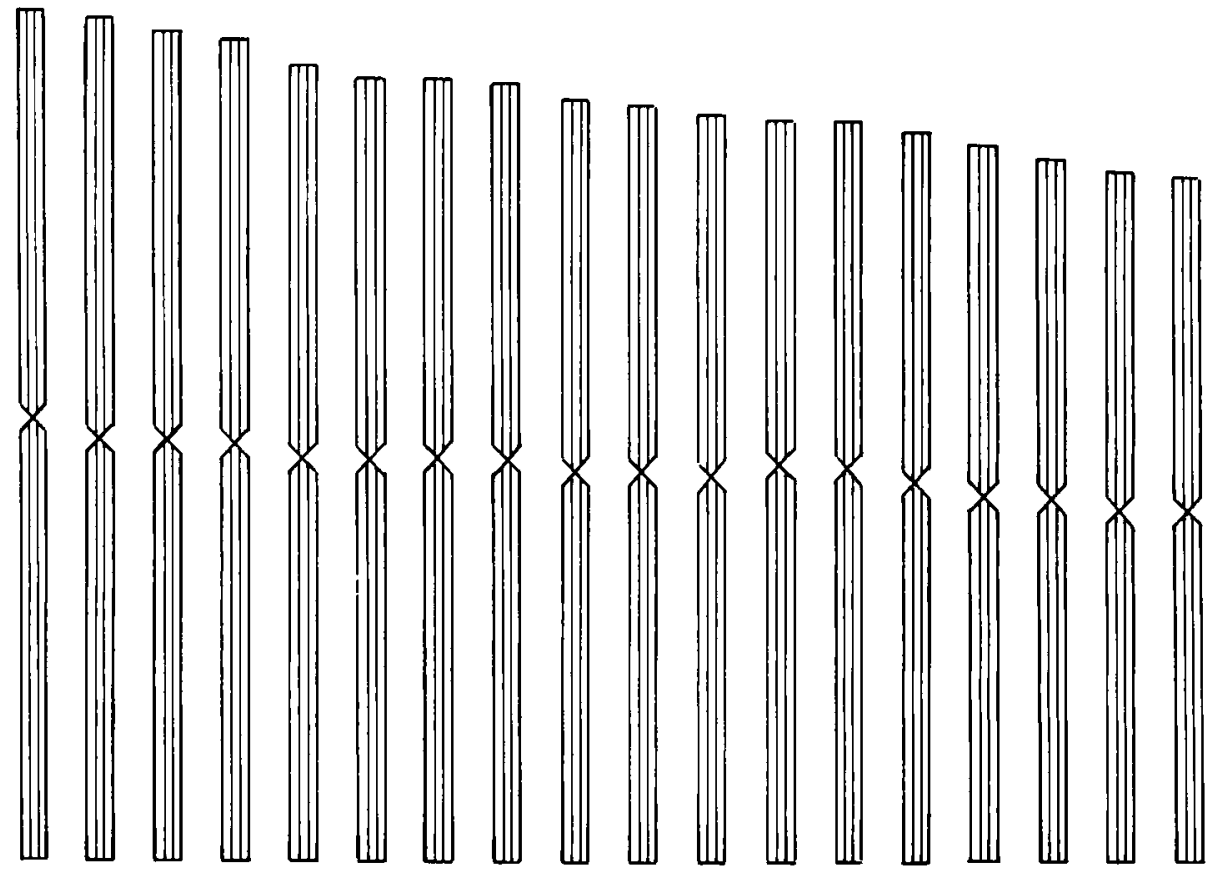

Fig. 5. Diagramatical representation of the karyotype of Gigantocypris muelleri based on the mean values of relative length and centromere indices, showing a very gradual decrease in length and metacentric position of the centromere. 
diploid number is relatively low, $18(16 \mathrm{~A}+\mathrm{XX})$ for the female and $17(16 \mathrm{~A}+\mathrm{XO})$ for the male.

Dietz $(1954,1958)$ and Tetart $(1975,1978)$ observed that the number of heterochromosomes present in the karyotypes of the males of freshwater ostracods is variable and that the male is usually heterogametic. Although the $\mathrm{X}$ chromosome is often unpaired $(\mathrm{XO})$ (as is also the case in the present study of $G$. muelleri), the presence of more than one $\mathrm{X}$ or more than one $\mathrm{Y}$ in the $\mathrm{XY}$ complements is also common.

The size of the chromosomes of Gigantocypris muelleri is many times larger than those of any freshwater podocopid ostracods. The smallest ranges approximately from $15 \mu \mathrm{m}-23 \mu \mathrm{m}$, according to the state of contraction in the metaphase concerned. The size of the largest chromosomes measured under the same conditions ranges from $21 \mu \mathrm{m}-27 \mu \mathrm{m}$ (see Fig. 3).

Although cytogenetic studies on marine invertebrates are not as numerous as on other groups, some work has been done in such groups as tunicates, echinoderms and copepods. Colombera \& Lazzaretto-Colombera (1978) indicated that a comparison of the karyotypes of the groups mentioned above shows that they are characterised by different patterns of chromosome evolution: "However, in these groups the course of evolution seems to have been consistently accompanied by decrease of chromosome number and DNA amounts and an increase in chromosome symmetry and uniformity"; (p. 514). "Moreover, when it is possible to define a species as highly specialized, its karyotype is always characterised by relatively low chromosome number, high chromosome symmetry and uniformity of chromosomal dimensions" (p. 514).

Tetart's concept of a 'symmetrical' karyotype is based on the presence of only one morphological type of chromosomes. These are elements with a centromere in distal position which he calls 'acrocentric'. The karyotype of Gigantocypris muelleri fits Tetart's definition of a 'symmetrical' karyotype only in part since, although all the elements are morphologically similar, these chromosomes are all metacentric rather than 'acrocentric'.

Following Tetart's (1978) reasoning, the increase in number of metacentric chromosomes present in a karyotype can be taken as an indication of to what degree the karyotype has evolved from a 'primitive' type. In all the species studied by Tetart, it is through this process that 'asymmetrical' karyotypes have derived.

Perhaps the use, by Tetart, of the words 'symmetrical' and 'asymmetrical' to indicate the presence of one or more morphological types of chromosome is unfortunate, since the great symmetry of a karyotype is better expressed by the presence of highly symmetrical metacentric chromosomes.

The conclusions reached by Tetart were restricted by the number of species, populations and individuals that he analysed. He expressed some natural reservations in committing himself to drawing any firm conclusions regarding the geographical variation of the karyotype and its possible reflection on the phenotype until further work could be carried out.

Nevertheless, some interesting results emerge from his work. He was able to establish main cytogenetical differences between the three superfamilies. These differences are of a numerical nature between the Cypridacea and Cytheracea, and of structural nature between these two groups and the Darwinulacea.

Although it is premature at this stage to relate the results of the present study to those of Tetart, the karyotype of this species of the Myodocopina shows some striking features which sets it apart from the Podocopina. The results are encouraging enough to consider the study of the cytogenetical characteristics of the Ostracoda as a useful tool in the understanding of their evolution.

The study of the cytogenetical characteristics of other marine myodocopid species is necessary before any firm conclusions can be drawn regarding the position of $G$. muelleri in the evolutionary plexus of the Ostracoda as a whole and before comparison in detail with freshwater forms can be made. A study of other species of this genus and other pelagic species of ostracods, which is projected by the author, may throw further light upon this problem.

However, taking into account the concepts discussed above and in particular those of Colombera \& Lazzaretto (1978), it may not be too unreasonable to suggest that G. muelleri, a highly specialised bathypelagic ostracod also has a highly evolved karyotype.

\section{ACKNOWLEDGEMENTS}

My grateful thanks are due to Drs. Martin Angel and Celia Ellis of the Institute of Oceanographic Sciences; to the former for making it possible to take part in the RRS 'Discovery' Cruise of 1981, for reading and commenting on part of the manuscript; to the latter for collecting additional material during 1983 . I would also like to extend my thanks to Dr. R. C. Whatley for critically reading the manuscript, and his constructive comments; and to Prof. J. R. Haynes for many valuable discussions. To Dr. Neil Jones of the Dept. of Agricultural Botany, U.C.W., Aberystwyth, I owe a great debt of gratitude for the generous way in which he has assisted in this project, by imparting so much of his knowledge with respect to both theoretical and practical genetics. My thanks are extended to Mr. H. Williams for his careful work in printing the final photographs.

\section{REFERENCES}

Angel, M. V.et al. 1981. RRSDiscovery Cruise 121: 5-26 June 1981. Biological investigations of the oceanic front to the south-west of the Azores. Institute of Oceanographic Sciences, Cruise Report, No. 115. Unpublished Manuscript. 
Baker, A. de C., Clarke, M. R. \& Harris, M. J. 1973. The N.I.O. combination net and further developments of rectangular midwater trawls. J. mar. biol. Ass. U.K., 53 (1), 167-184.

Bauer, H. 1934. Geschlechtschromosomen bei Ostracoden. Naturwissenschaften, $22,543$.

Bauer, H. 1940. Uber die Chromosomen der bisexuellen und der parthenogenetischen Rasse des Ostracoden Heterocypris incongruens Rand. Chromosoma 1, 620-637.

Bianchi Bullini, Anna P. \& Bullini, L. 1972. Osservazioni sul corredo cromosomico di Eucypris virens e di Cypris bispinosa (Crustacea, Ostracoda). Lincei-Rend. Sc. fis. mat. e nat., LII, 423-426.

Colombera, D. \& Lazzaretto-Colombera, Ivana. 1978. Chromosome evolution in some marine invertebrates. In Battaglia, B. \& Beardmore, J. A. (Eds.), Marine organisms, genetics, ecology, and evolution, 487-525.

Dietz, R. 1954. Multiple Geschlechtschromosomen bei dem Ostracoden Notodromas monacha. Chromosoma, 6, 397 418.

Dietz, R. 1955. Zahl und Verhalten der Chromosomen einiger Ostracoden. Z. Naturf. 10, 92-95.

Dietz, R. 1958. Geschlechtschromosomen bei den Cypriden Ostracoden, ihre Evolution und ihr Teilungsverhalten. Chromosoma, 9, 359-440.

Herring, P. J. et al. 1983. RRS Discovery Cruise 140: Leg 1, 5-22 August 1983. Leg 2, 22 August - 13 September 1983. Biological and physiological studies in the eastern North Atlantic (15N-45N). Institute of Oceanographic Sciences, Cruise Report, No. 155, 47 pp.
Macgregor, H. C. \& Varley, J. M. 1983. Working with animal chromosomes, 250 pp. John Wiley \& Sons.

Moguilevsky, A. \& Gooday, A. J. 1977. Some observations on the vertical distribution and stomach contents of Gigantocypris muelleri Skogsberg 1920 (Ostracoda, Myodocopina), 263-270. In Loffler, H. \& Danielopol, D. (Eds.), Proceedings 6th. International Symposium on Ostracods, Saalfelden (Salzburg), July 30 - August 8, 1976. Dr. W. Junk b.v. Publishers, The Hague, $521 \mathrm{pp}$.

Muller-Cale, K. 1913. Uber die Entwicklung von Cypris incongruens. Zool. Jb., Abt., Anat. u. Ontog., 36, 113-170.

Schleip, W. 1909. Vergleichende Untersuchungen der Eireifung bei parthenogenetisch und bei geschlechtlich sich fortpflanzenden ostracoden. Arch. Zellforsch., 8, 390-431.

Schmalz, J. 1912. Zur Kenntnis der Spermatogenese der Ostracoden. Arch. Zellforsch., 8, 407-441.

Tetart, J. 1967. Étude des garnitures chromosomiques de quelques Ostracodes d'eau douce. Bull. Soc. Zool. Fr., 92, 167-176.

Tetart, J. 1969. Technique d'etalement des chromosomes d'Invertebres. Bull. Soc. Zool. Fr., 94, 251-254.

Tetart, J. 1975. Recherches sur la reproduction et l'ecologie de quelques Ostracodes Cyprididae. These, U. S. M., Grenoble.

Tetart, J. 1978. Les garnitures chromosomiques des Ostracodes d'eau douce. Trav. Lab. Hydrobiol., 69-70, 113-140. Grenoble.

Woltereck, R. 1898. Zur Bildung und Entwicklung des Ostracoden-Eies. Kerngeschichtliche und biologische Studien an parthenogenetischen Cypriden. Z. Wiss. Zool., 64, 596-623. 